\title{
Improvements in colorectal cancer screening programmes - quantitative immunochemical faecal occult blood testing - how to set the cut-off for a particular population
}

\author{
Jaroslava Tereza Kovarovaa , Miroslav Zavoral ${ }^{\mathrm{b}}$, Tomas Zima ${ }^{c}$, Ales Zaka, , Petr Kocnac, \\ Pavel Kohout d, Jana Granatova ${ }^{\mathrm{e}}$, Zdislava Vanickova', Jana Vranova ${ }^{\mathrm{f}}$, Stepan Suchanek ${ }^{\mathrm{b}}$, Zdenek Benes ${ }^{\mathrm{d}}$, \\ Martin Alexander Celko", Ctibor Povysil ${ }^{\mathrm{h}}$
}

\begin{abstract}
Objective. The aim of the study was to determine the optimum cut-off value of the quantitative immunochemical test (q-FIT) OC-Sensor ${ }^{\circledast}$ for colorectal cancer and advanced adenomatous polyps in a particular population.

Methods. 815 patients were referred for colonoscopy and were offered two q-FIT examinations at two different colonoscopy centers. The patients were classified according to the colonoscopic findings. Test sensitivity, specificity, and accuracy were statistically evaluated using one test and two tests at the levels of $50,75,100,125$, and $150 \mathrm{ng} / \mathrm{mL}$ of faecal hemoglobin in those patients with advanced polyps and colorectal cancer. The optimum cut-off test level for clinically significant neoplasia was determined using one test.

Results. The optimum cut-off value of q-FIT OC-Sensor for the detection of clinically significant neoplasia in our particular population was determined as $75 \mathrm{ng} / \mathrm{mL}$ using one test. This value provides an optimum proportion of $73 \%$ sensitivity $( \pm 95 \% \mathrm{Cl} 60.3 \%-83.4 \%)$ and $90 \%$ specificity $( \pm 95 \% \mathrm{Cl} 86.8 \%-92.8 \%), \mathrm{PPV}$ and NPV were determined as $54.76 \%$ and $95.43 \%$ respectively.

Conclusions. The first step in the implementation of q-FIT test in the screening program in our country is to determine the optimum cut-off level for a population, and to estimate the number of tests performed with respect to the optimum cost effectiveness and economical climate. Using one test, the optimum level of q-FIT OC-Sensor ${ }^{\otimes}$ in the Czech Republic was determined as $75 \mathrm{ng} / \mathrm{mL}$. This study could serve as a model for further studies in other countries, where screening does not yet exist.
\end{abstract}

Key words: cut-off, quantitative immunochemical test, colorectal cancer, screening, Czech Republic

Received: October 7, 2011; Accepted: February 27, 2012; Available online: June 1, 2012

http://dx.doi.org/10.5507/bp.2012.030

${ }^{a} 4$ th Department of Internal Medicine, General Teaching Hospital, First Faculty of Medicine, Charles University Prague, Czech Republic ${ }^{b}$ Department of Internal Medicine, Central Military Hospital, First Faculty of Medicine, Charles University Prague 'Department of Clinical Chemistry and Laboratory Diagnostics, First Faculty of Medicine, Charles University Prague

${ }^{d}$ 2nd Department of Internal Medicine, Thomayer Teaching Hospital Prague

${ }^{e}$ Department of Clinical Chemistry, Thomayer Teaching Hospital Prague

${ }^{f}$ Department of Medical Biophysics and Informatics, Third Faculty of Medicine, Charles University Prague

${ }^{9}$ Department of Epidemiology, Third Faculty of Medicine, Charles University Prague

${ }^{h}$ Department of Pathology, First Faculty of Medicine, Charles University Prague

Corresponding author: Jaroslava Tereza Kovarova, e-mail:s.l.a.v.k.a@seznam.cz

\section{INTRODUCTION}

The epidemiology of colorectal cancer (CRC) in the Czech Republic (CR) is extremely unfavorable ${ }^{1,2}$. The Czech Republic has one of the highest incidences of and mortality from colorectal cancer in the world. An alarming incidence rate $(79 / 100,000)$ and mortality rate $(45 / 100,000)$ exists and has remained almost unchanged over the past few years. For this reason, the National Colorectal Cancer Screening Program was launched in 2000 (ref. ${ }^{1}$ ). It was focused on asymptomatic persons older than 50 years of age who were offered faecal occult blood test (FOBT), followed by colonoscopy in those cases with positive results.
Guaiac-based tests were solely used during the early years of the screening program ${ }^{3}$. Guaiac-based FOBTs (gFOBTs) (ref. ${ }^{3,4}$ ) are based on the pseudoperoxidase reaction of hemoglobin with guaiac resin in the presence of hydrogen peroxide. These tests are only qualitative, thus giving only positive or negative results. They have low sensitivity for advanced adenomatous polyps and carcinomas ( $11 \%$ and $13 \%$, respectively) and relatively low specificity for human hemoglobin. Therefore, a convenient low peroxidase diet should be introduced and maintained before testing.

G-FOBTs are still mostly used in Europe, but some European countries have changed to immunochemical tests (FIT) $\left(\right.$ ref. $^{5-7}$ ) such as France and Italy while other 
countries will introduce it ie. Slovenia, The Netherlands and Germany.

Immunochemical tests had already become available during the first years of the screening program, with the use of specific antibodies against human hemoglobin and without dietary restriction. FITs are specific for human hemoglobin and, moreover, they possess a sensitivity which is almost twice as high as g-FOBT ${ }^{4,5,8}$. FITs are qualitative tests as well and as some recent studies show, the quality of individual FIT testing varies markedly ${ }^{6}$.

At the beginning of 2009, the method of the screening program in the Czech Republic was improved by the introduction of primary screening colonoscopy as the method of choice for patients age 55 years.

Recently, a new generation of quantitative FIT (qFIT) (ref. ${ }^{9}$ ) testing has become available, the advantage of which is to obtain optimum test sensitivity and specificity for a particular population by setting a cut-off value. A new more sophisticated sampling technology in immunochemical testing may lead to the growing participation of the population in the screening programme as well ${ }^{7}$. Some studies have also indicated greater patient participation in screening using q-FIT than g-FOBT ${ }^{10-12}$.

In our study performed in a Czech population with a high incidence of colorectal cancer, an optimum cut-off value of q-FIT was determined, and, with respect to the economic considerations, optimum parameters were set for performing one test. Thus, conditions for using q-FIT in our population within the ongoing screening program were prepared. This kind of clinical research could serve as a model for further studies in other European countries, where screening does not yet exist, before an expensive screening program is embarked upon nationwide.

\section{PATIENTS AND METHODS}

Patients: Between February 2008 and March 2009 we invited 1000 ambulatory patients referred consecutively for colonoscopy at two endoscopy centers for participation in the study. Some patients were asymptomatic and were invited for elective colonoscopy, some patients were in the high risk category for colorectal cancer (from both centers), and some patients were symptomatic and were referred by their GPs (Table 1). Exclusion criteria were hematuria or menstruation at the time of the sample collection, a known diagnosis of IBD, visible rectal bleeding and an inability in stool collection. Patients on anticoagulant therapy (it was stopped for colonoscopy) and patients using non-steroidal anti-inflammatory drugs were not excluded ${ }^{13}$ (Table 2). A complete colonoscopy was performed in 682 patients $(83.7 \%)$ out of an initial number of 815 patients (410 males, 405 females, with a mean age 57.4 years). Study subjects with incomplete or inadequate colonoscopy examination were given contrast barium enemas or CT colonography and were additionally included. However patients having incomplete colonoscopies without the aforementioned additional investigations were excluded (Table 2). Complete colonoscopy was de- fined as intubation to the lower caecum or intubation up to an obstructing neoplasm.

The number and size of any polyps and their location were recorded; biopsies were taken of all abnormal lesions. Colonoscopies were performed by four experienced colonoscopists. Histological examinations of bioptic samples were reviewed by a pathologist and uncertain results were re-evaluated by a second pathologist. The degree of dysplasia of any resected polyps was determined according to the Vienna classification system ${ }^{14,15}$.

Patients were then separated into three groups according to their colonoscopic and histological findings (Table 3).

A. The control group (group C): a group of healthy patients and patients with hemorrhoids - 445 patients (189 healthy persons +226 persons with hemorrhoids).

B. The group with non-advanced polyps (group 1): a group of patients with polyps up to $1 \mathrm{~cm}$ with histology V1-V3 according to the Vienna classification system 161 patients

C. The group with clinically significant neoplasia (group 2): this group of 63 patients consisted of those with advanced polyps, i.e. polyps of size $\geq 10 \mathrm{~mm}$ with V4 histology according to the Vienna classification system 28 patients (group 2-V4) and patients with carcinomas, i.e. histology V5 according to Vienna classification system - 35 patients (group 2-V5). All the results are summarized in Table 3 and in Fig. 1.

\section{Methods:}

Tests and sample collection: The patients obtained two quantitative immunochemical tests OC-Sensor ${ }^{\circledR}$ (Eiken

Table 1. Basic sample characteristics.

\begin{tabular}{lc}
\hline Characterictic & Value [\%] \\
\hline Total Patients & $815[100]$ \\
Men & $410[50.3]$ \\
Women & $405[49.7]$ \\
Mean age & 57.4 \\
\hline Indications & Value [\%] \\
\hline Past colorectal & $295[36]$ \\
neoplasia & \\
Positive FOBT & $122[15]$ \\
Family history of CRC & $65[8]$ \\
Anaemia & $81[10]$ \\
Abdominal pain & $57[7]$ \\
Weight loss & $73[9]$ \\
Change of bowel habit & $106[13]$ \\
Other & $16[2]$ \\
\hline
\end{tabular}




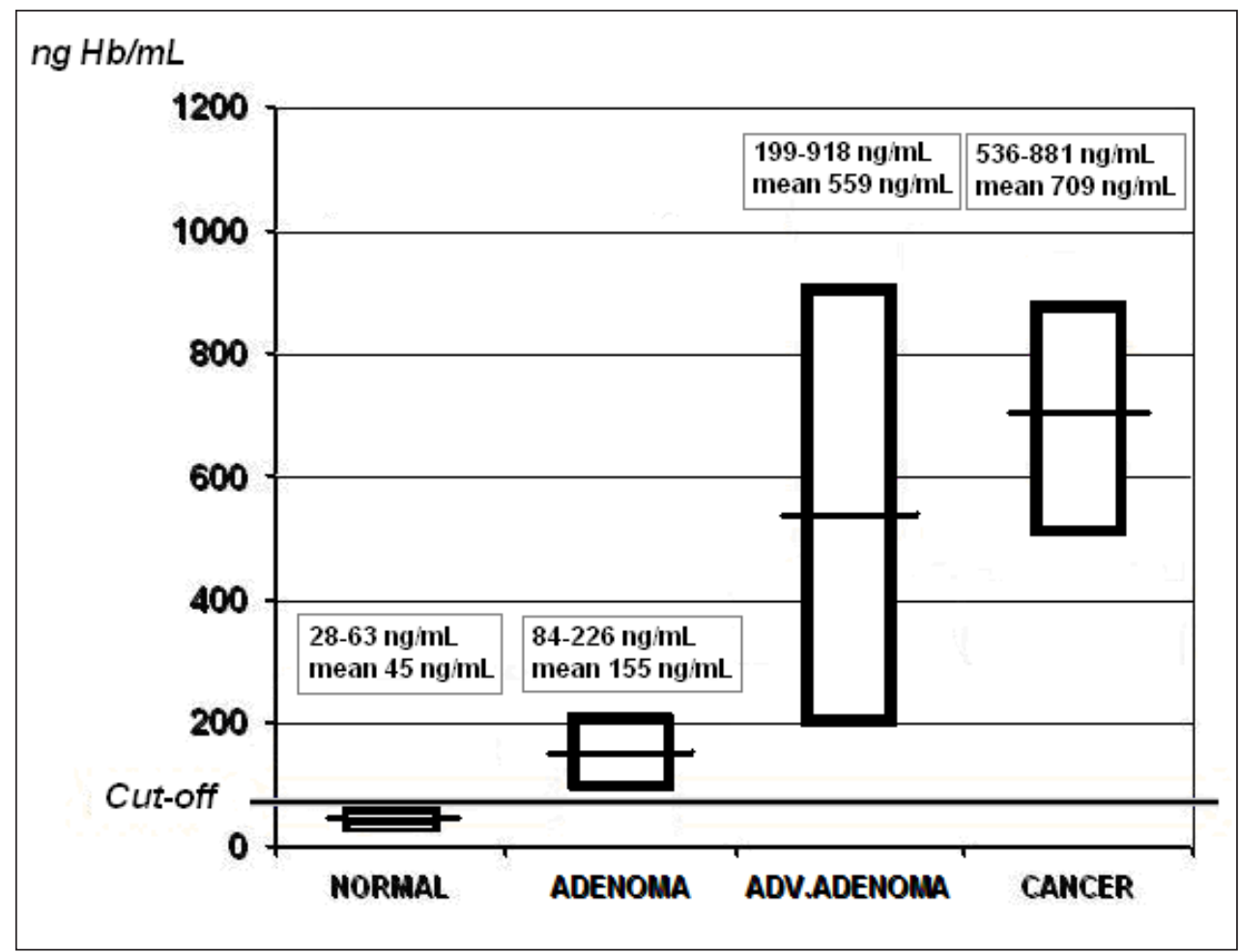

Fig. 1. Cut-off $75 \mathrm{ng} / \mathrm{mL}$ for q-FIT and results of the first test in different groups of patients.

Table 2. Study flow chart.

\begin{tabular}{|c|c|c|c|}
\hline Invited for participation in the study & 1000 & & \\
\hline Included (recieved FIT) & $815[100 \%]$ & Excluded & 185 \\
\hline Completed & 709 [87\%] & Hematuria & 15 \\
\hline Complete colonoscopy & $682[83.7 \%]$ & Menstruation & 20 \\
\hline $\begin{array}{l}\text { Incomplete colonoscopy }+ \text { contrast } \\
\text { barium enema or CT colography }\end{array}$ & $27[3.3 \%]$ & Rectal bleeding & 74 \\
\hline \multirow{2}{*}{$\begin{array}{l}\text { Not completed (incomplete colonos- } \\
\text { copy or poor preparation without next } \\
\text { examination) }\end{array}$} & \multirow{2}{*}{$\begin{array}{c}106[13 \%] \\
(82[10.1 \%]+24[2.9 \%])\end{array}$} & IBD & 72 \\
\hline & & Other & 4 \\
\hline
\end{tabular}

Chemical Co., Tokyo, Japan) (ref. ${ }^{9}$ ) at the time of colonoscopy scheduling 9 . All patients obtained both verbal as well as written instructions about the test. The samples were collected from two separate bowel movements at intervals of 1 to 5 days prior to preparation for colonoscopy using a special collecting stick on the kit cover. The collecting stick with attached stool was immediately inserted into a test tube and stored in the refrigerator. The date of stool collection was recorded and the tubes were delivered immediately prior to colonoscopy ${ }^{16}$.

q-FIT analysis: A quantitative immunochemical faecal occult blood test OC-Sensor ${ }^{\circledR}$ was analyzed using the immuno-turbidimetric method with an OC-Sensor $\mu$ analyzer (Eiken Chemical Co., Tokyo, Japan). Monoclonal human $\mathrm{HbA} 0$ antibodies sensitized by latex, reacted with hemoglobin in the sample producing the subsequent latexagglutination reaction. The optical density of the reaction solution increased together with the growing concentra- tion of $\mathrm{HbA} 0$ in the sample, and the changes in optical density were subsequently analyzed.

Statistical evaluation: We compared areas under the ROC curve for both the first test (HGB1) and the highest value of the two tests performed (HGB2), using Z-statistics according to Hanley and $\mathrm{McNei}^{17}$. This was to determine which of the values had the greater discriminative power and also to determine whether we needed only one test or two tests to adequately distinguish between healthy patients and those with significant neoplasia. Statistical analysis was performed at the levels of 50, $75,100,125$, and $150 \mathrm{ng} / \mathrm{mL}$. Software SPSS version 17 (SPSS Inc.) and STATISTICA version 7.1 (STATSOFT Inc.) were used for statistical calculations. The statistical significance of all tests was determined at the level of $P \leq 0.05$.

The study was performed with the approval of the ethics committees of both participating centers. (The 
Table 3. Results of measurement using one test (HGB1) and using two tests (HGB2).

\begin{tabular}{lccc}
\hline & Patients n (\%) & \multicolumn{2}{c}{ Mean \pm SD[ \pm 95\% CI] } \\
\hline Characteristic & & HGB 1 & HGB 2 \\
A: Controls (n=415) - Group C & & & \\
Healthy & $189(25.82)$ & $26.43 \pm 82.23$ & $48.50 \pm 143.22$ \\
& & {$[74.69-91.47]$} & {$[130.095-159.32]$} \\
Hemorrhoids & $226(30.87)$ & $61.26 \pm 233.80$ & $97.52 \pm 338.31$ \\
& & {$[214.05-257.60]$} & {$[309.73-372.74]$} \\
All normal cases & $415(56.69)$ & $45.40 \pm 181.88$ & $75.20 \pm 268.54$ \\
& & {$[170.29-195.18]$} & {$[251.43-288.17]$} \\
Cases (total classified, n = 224) & & \\
& & & \\
V1 & $34(15.18)$ & $258.32 \pm 700.81$ & $293.15 \pm 733.38$ \\
& & {$[565.26-922.46]$} & {$[591.52-965.33]$} \\
V2 & $23(10.27)$ & $15.96 \pm 32.31$ & $21.91 \pm 34.10$ \\
& & {$[24.99-45.74]$} & {$[26.37-48.27]$} \\
V3 & $104(46.43)$ & $152.15 \pm 398.33$ & $227.31 \pm 534.77$ \\
& & {$[350.57-461.57]$} & {$[470.66-619.28]$} \\
B: All non advanced adenomas & $161(71.88)$ & $155.12 \pm 456.77$ & $211.87 \pm 549.49$ \\
(V1 + V2 + V3) - Group 1 & & {$[411.73-512.95]$} & {$[495.31-617.08]$} \\
V4 & $28(12.50)$ & $558.87 \pm 927.08$ & $722.86 \pm 997.14$ \\
& & {$[732.96-1261.88]$} & {$[788.36-1357.25]$} \\
V5 (Carcinomas) & $35(15.63)$ & $708.80 \pm 501.97$ & $877.63 \pm 640.44$ \\
& & {$[406.03-657.68]$} & {$[518.03-839.10]$} \\
C: Clinically significant neoplasia & $63(28.12)$ & $642.03 \pm 719.81$ & $808.84 \pm 814.82$ \\
(V4+V5) - Group 2 & & {$[612.41-873.25]$} & {$[693.24-988.52]$} \\
\hline
\end{tabular}

V1 negative for neoplasia/dysplasia, V2 indefinite for neoplasia/dysplasia, V3 non-invasive low grade neoplasia (low grade adenoma/dysplasia), V4 non-invasive high grade neoplasia (high grade adenoma/dysplasia and non-invasive carcinoma), V5 invasive neoplasia (intramucosal carcinoma, submucosal carcinoma or beyond).

General Teaching Hospital and The Thomayer Teaching Hospital, both in Prague). The entire data were statistically processed, all patients gave their written informed consent and strict anonymity and confidentiality were maintained at all times.

\section{RESULTS}

In the group with clinically significant neoplasia (advanced polyps and carcinomas) (Group 2, V4+V5), sensitivity and specificity at the level of $50 \mathrm{ng} / \mathrm{mL}$ were $76.2 \%$ $( \pm 95 \%$ CI $63.8 \%-86.0 \%)$ and $87.2 \%( \pm 95 \%$ CI $83.6 .3 \%$ - $90.2 \%)$, using one test, and $77.8 \%$ ( $\pm 95 \%$ CI $65.5 \%-$ $90.2 \%)$ and $81.4 \%( \pm 95 \%$ CI $77.3 \%-85.0 \%)$, using the highest value of two tests. For the carcinoma subgroup (Group 2-V5), sensitivity and specificity at the level of 50 $\mathrm{ng} / \mathrm{mL}$ was $88.6 \%( \pm 95 \%$ CI $73.2 \%-96.7 \%)$ and $87.2 \%$ $( \pm 95 \%$ CI $83.6 \%-90.2 \%)$, using one test, and $88.6 \%$ $( \pm 95 \%$ CI $73.2 \%-96.7 \%)$ and $81.4 \%( \pm 95 \%$ CI $77.3 \%-$ $85.0 \%)$, using two tests. These results and the results for the levels of $75,100,125$, and $150 \mathrm{ng} / \mathrm{mL}$ are summarized in Table 4. Based on these values, an optimum level was chosen for the clinically significant neoplasia group (V4 + V5). Using two tests at such a level when the sensitivity was sufficiently high, allowed assessment of the influence on the number of false positive results. Again, virtually similar results of sensitivity and specificity were found using one test.

The best results in the group with clinically significant neoplasia using one test were found at the level of $75 \mathrm{ng} / \mathrm{mL}$ with a sensitivity and specificity $73.0 \%( \pm 95 \%$ CI $60.3 \%-83.4 \%)$ and $90.1 \%$ ( $\pm 95 \%$ CI $86.8 \%-92.8 \%)$, respectively. Using one test at this level, a of sensitivity $85.7 \%( \pm 95 \%$ CI $69.7 \%-95.1 \%)$ and specificity of $90.1 \%$ $( \pm 95 \%$ CI $86.8 \%-92.8 \%)$ were obtained in the carcinoma group (V5). The level of $75 \mathrm{ng} / \mathrm{mL}$ renders the best sensitivity/specificity ratio for q-FIT for performing one test.

For one test, the mean test value was $708 \mathrm{ng} / \mathrm{mL}$ [ $\pm 95 \%$ CI 536.37-881.23] in the carcinoma group, $559 \mathrm{ng} / \mathrm{mL}$ [ $\pm 95 \%$ CI 199.09-918.05] in the adenoma group and in the joint group of carcinomas and advanced adenomas, the mean value was $642 \mathrm{ng} / \mathrm{mL}$ [ $\pm 95 \% \mathrm{CI}$ 460.75-823.31]. The patients repeat this test each year in accordance with our screening program.

The area under the ROC curve for the first test (HGB1) was not significantly different from the area under the ROC curve for the two tests (HGB-Higher) (graph 2). The significance of the Z-test according to Hanley and Mc Neil ${ }^{17}$ was $P=0.86$. Graph 2 shows that the curves 


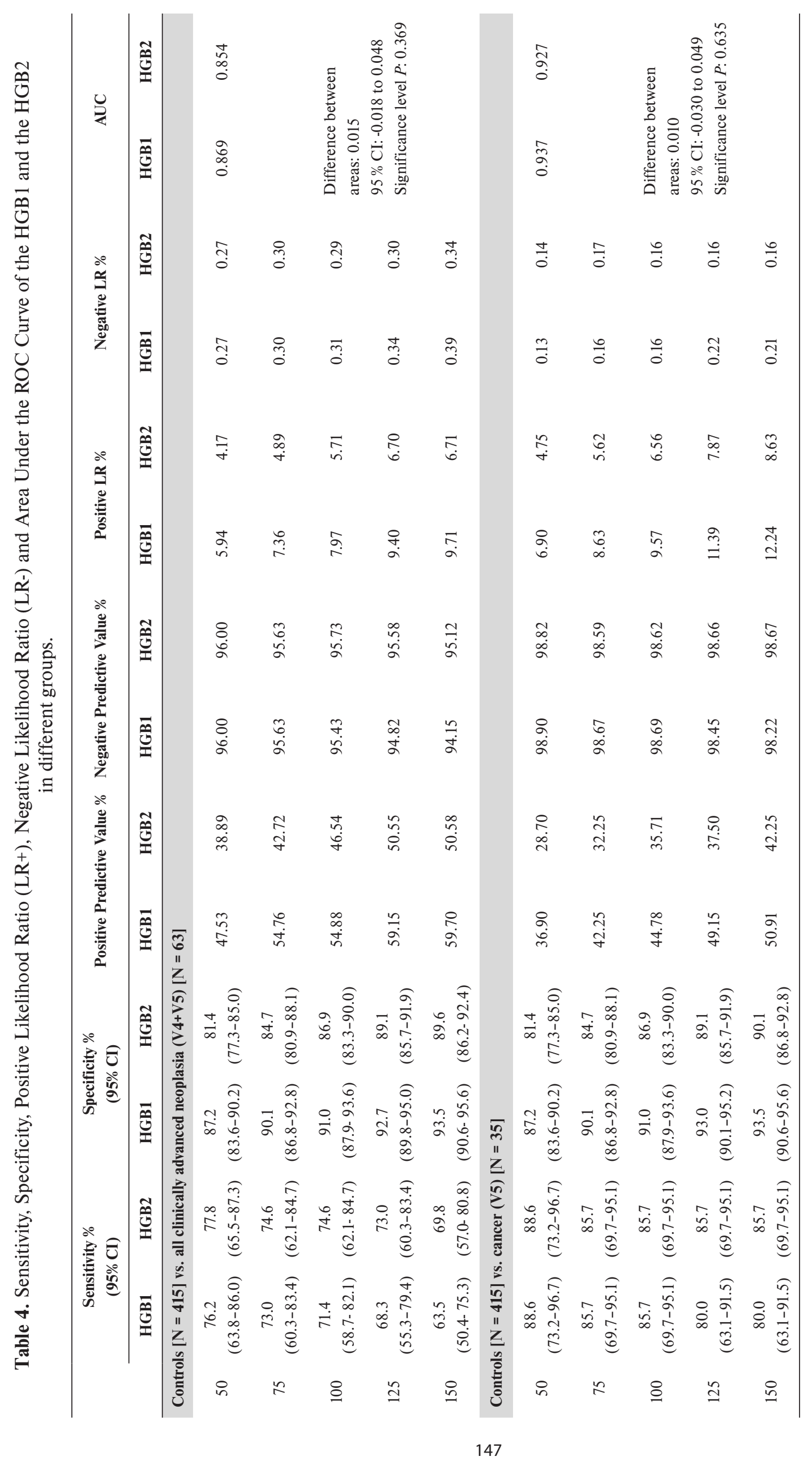






Fig. 2. Com parison of two ROC curves for the First and the Higher Measurements of two q-FITs (Controls vs. advanced neoplasia (cancer and advanced polyps)).

Area under the ROC curve $=0.869 .95 \%$ Confidence interval $=0.835$ to 0.898

HGB Higher: Area under the ROC curve $=0.854$. $95 \%$ Confidence interval $=$ 0.819 to 0.884

Difference between areas $=0.015$. Standard error $=$ 0.017. $95 \%$ Confidence interval $=-0.018$ to 0.048 Significance level $P=0.369$

for both variables almost overlap, i.e. both variables possess the same resolving power. This observation was confirmed by means of the t-test ( $P>0.05$; Fig. 2$)$.

\section{DISCUSSION}

The incidence and mortality rates for colorectal cancer differ markedly in the populations of individual European countries, each having different eating habits and genetic predispositions ${ }^{2}$. For this reason, each population, not only Europeans, should be assessed with respect to possible diversity. Therefore we decided, prior to the introduction of q-FIT into the screening program, to test our population, which is remarkable for its very high incidence of colorectal cancer and mortality, and to determine a cut-off limit for the Czech population. Considering economic aspects, we took advantage of qFIT to achieve an increase in test sensitivity by decreasing the cut-off value and, with respect to specificity; we chose the best cut-off point using a q-FIT. The technology of qFIT ensures ideal sensitivity/specificity ratio by virtue of the quantitative results ${ }^{18-21}$.

The lower proportion of complete colonoscopies in our survey was due to the exclusion of patients with poor preparation who were not willing to undergo repeated colonoscopy within the specified time-frame.

The patient population is not absolutely identical to the screening population. Therefore, the results of this study are to be verified in the future within a large population including the screening population.

q-FIT is a cheap method compared to colonoscopy. In the case of false positive tests, subsequent colonoscopy is feasible because patients in this country undergo primary screening colonoscopy (ie.colonoscopy without previous faecal occult blood test in patients older than 55 years) $)^{2}$. On the other hand, delayed diagnosis due to false negative tests may have serious impact on patient survival and subsequent quality of life. Hence, test sensitivity was strongly emphasized when the correct cut-off value as $75 \mathrm{ng} / \mathrm{mL}$ was determined. Relatively low specificity $90 \%$ is tolerable in a country with alternatively proceeding primary colonoscopy screening. Slightly better results were obtained by performing two tests and the results were corrected by lowering the cut-off level when performing one test ${ }^{21,22}$. If the capacity of the endoscopic centers is sufficient, the value $75 \mathrm{ng} / \mathrm{mL}$ is optimum and can be recommended.

A number of studies have reported the advantages of q-FIT ${ }^{23-27}$. The advantage of q-FIT over g-FOBT lies in the recognition of a larger number of early cancers and adenomatous lesions ${ }^{25}$. Better results from this newer test will also play a favorable role in the psychological influence of both general practitioners and patients, which may help to decrease the relatively high proportion of unperformed colonoscopies despite a positive FOBT ${ }^{28,29}$.

In the processing of liquid q-FIT kits, time-dependency is an important consideration compared to g-FOBT dry kits $^{16}$. In addition, the storage temperature, which is im- 
portant for both types of tests, is logistically more demanding in the case of q-FIT and will require changes in the organization of the screening programme.

Despite primary colonoscopy screening being available in the Czech Republic as a "gold standard" for persons older than 55 years, FIT performed on an annual basis from the age of 50 years may be the next option. We expect a significant portion of the screening population will use the q-FIT (ref. ${ }^{30}$ ). With respect to the high quality of colonoscopic procedures, a high-quality but less invasive alternative should be offered.

\section{CONCLUSION}

The number of tests performed in each country will be determined by its economic viability.

Determination of an optimum cut-off point for a particular population should be the first step toward the introduction of q-FIT into the screening programme. For the Czech Republic, this level was determined as $75 \mathrm{ng} /$ $\mathrm{mL}$ using one test. It could serve as a model for further studies in other countries where colorectal screening does not yet exist.

The next step in the verification of the results should be the use of q-FIT within a large study including the screening population of a particular country.

The final goal is a marked improvement in epidemiological parameters, i.e. colorectal cancer incidence and mortality, than was accomplished by g-FOBT.

\section{ACKNOWLEDGEMENT}

Supported by the Research grant number VZ MZO 00064165 (VZ0VFN2005).

\section{REFERENCES}

1. Zavoral M. Colorectal cancer screening in the Czech Republic Z Gastroenterol 2008:46(Suppl 1):29-30.

2. Zavoral M, Suchanek S, Zavada F, Dusek L, Muzik J, Seifert B, Fric P. Colorectal cancer screening in Europe. World J Gastroenterol 2009; 15:5907-915

3. Mandel JS, Bond JH, Church TR, Snover DC, Bradley GM, Schuman LM, Ederer F. Reducing mortality from colorectal cancer by screening for fecal occult blood. N Engl J Med 1993;328:1365-71.

4. Hardcastle JD, Chamberlain JO, Robinson MH, Moss SM, Amar SS, Balfour TW, James PD, Mangham CM. Randomised controlled trial of faecal-occult-blood screening for colorectal cancer. Lancet 1996;348:1472-77.

5. Crotta S, Castiglione G, Grazzini G, Valle F, Mosconi S, Rosset R. Feasibility study of colorectal cancer screening by immunochemical faecal occult blood testing: results in a nothern Italian community. Eur J Gastroenterol Hepatol 2004;16:33-7.

6. Hundt S, Haug U, Brenner H. Comparative evaluation of immunochemical fecal occult blood tests for colorectal adenoma detection. Ann Intern Med 2009;150:162-9.

7. Young GP, Cole S. New stool screening tests for colorectal cancer. Digestion 2007;76:26-33.

8. Shapiro JA, Seeff LC, Thompson TD, Nadel MR, Klabunde CN, Vernon SW. Colorectal cancer test use from the 2005 National Health
Interview Survey. Cancer Epidemiol Biomarkers Prev 2008;17:162330.

9. Levi Z, Rozen P, Hazazi R, Vilkin A, Waked A, Maoz E, Birkenfeld S, Leshno M, Niv Y. A quantitative immunochemical fecal occult blood test for colorectal neoplasia. Ann Intern Med 2007;146:244-55.

10. Vogt W. Prevention of colorectal cancer - update 2008. Praxis 2008;97:1077-83.

11. Van Rossum LG, Van Rijn AF, Laheij RJ, van Oijen MG, Fockens P, van Krieken $\mathrm{HH}$, Verbeek AL, Jansen JB, Dekker E. Random comparison of guajac and immunochemical fecal occult blood test for colorectal cancer in screening population. Gastroenterology 2008;135:82-90.

12. Hol $L$, van Leerdam $M E$, van Ballegooijen $M$, van Vuuren $A J$, van Dekken H, Reijerink JC, van der Togt AC, Habbema JD, Kuipers EJ. Screening for colorectal cancer; randomised trial comparing guaiacbased and immunochemical faecal occult blood testing and flexible sigmoidoscopy. Gut 2010;59:62-8.

13. Levi Z, Rozen P, Hazazi R, Vilkin A, Waked A, Maoz E, Birkenfeld S, Lieberman N, Klang S, Niv Y. Sensitivity, but not specificity, of a quantitative immunochemical fecal occult blood test for neoplasia is slightly increased by the use of low dose Aspirin, NSAIDS, and anticoagulants. Am J Gastroenterol 2009;104:933-8.

14. Schlemper RJ, Riddell RH, Kato Y, Borchard F, Cooper HS, Dawsey SM, Dixon MF, Fenoglio-Preiser CM, Fléjou JF, Geboes K, Hattori T, Hirota T, Itabashi M, Iwafuchi M, Iwashita A, Kim YI, Kirchner T, Klimpfinger M, Koike M, Lauwers GY, Lewin KJ, Oberhuber G, Offner F, Price AB, Rubio CA, Shimizu M, Shimoda T, Sipponen P, Solcia E, Stolte M, Watanabe $\mathrm{H}$, Yamabe $\mathrm{H}$. The Vienna classification of gastrointestinal epithelial neoplasia. Gut 2000;47:251-5.

15. Winawer SJ, Zauber AG. The advanced adenoma as the primary target of screening. Gastroinest Endosc Clin N Am 2002;12:1-9.

16. Brown LF, Fraser CG. Effect of delay in sampling on haemoglobin determined by faecal immunochemical tests. Ann Clin Biochem 2008;45:604-5.

17. Hanley JA, McNeil BJ. A Method of Comparing the Areas under the Receiver Operating Curves Derived from the Same Cases. Radiology 1983;148:839-43.

18. Nakama $H$, Zhang B, Zhang X. Evaluation of the optimum cut-off point in immunochemical occult blood testing in screening for colorectal cancer. Eur J Cancer 2001;37:398-401.

19. van Rossum LG, van Rijn AF, Laheij RJ, van Oijen MG, Fockens $P$ Jansen JB, Verbeek AL, Dekker E. Cutoff value determines the performance of a semi-quantitative immunochemical faecal occult blood test in a colorectal cancer screening programme. Br J Cancer 2009;101:1274-81.

20. Vilkin A, Rozen P, Levi Z, Waked A, Maoz E, Birkenfeld S, Niv Y. Performance characreristics and evaluation of an automateddeveloped and quantitative, immunochemical, fecal occult blood screening test. Am J Gastroenterol 2005;100:2519-25.

21. Rozen $P$, Levi Z, Hazazi R, Waked A, Vilkin A, Maoz E, Birkenfeld S Leshno M, Niv Y. Identification of colorectal adenomas by a quantitative immunochemical fecal occult blood screening test depends on adenoma characteristics, development threshold used and number of tests performed. Aliment Pharmacol Ther 2009;29:906-17.

22. Grazzini G, Visioli CB, Zorzi M, Ciatto S, Banovich F, Bonanomi AG, Bortoli A, Castiglione G, Cazzola L, Confortini M, Mantellini P, Rubeca T, Zappa M. Immunochemical fecal occult blood test: number of samples and positivity cutoff. What is the best strategy for colorectal cancer screening? Br J Cancer 2009;100:259-65.

23. Deutekom M, van Rossum LG, van Rijn AF, Laheij RJ, Fockens $P$, Bossuyt PM, Dekker E, Jansen JB. Comparison of guaiac and immunological fecal occult bloos tests in colorectal cancer screening: the patient perspective. Scand J Gastroenterol. 2010;45:1345-9.

24. Park DI, Ryu S, Kim YH, Lee CK, Eun CS, Han DS. Comparison of Guaiac-based and quantitative immunochemical fecal occult blood testing in a population at average risk undergoing colorectal cancer screening. Am J Gastroenterol 2010;105:2017-25.

25. Levi Z, Hazazi R, Rozen P, Vilkin A, Waked A, Niv Y. A quantitative immunochemical faecal occult blood test is more efficient for detecting significant colorectal neoplasia than a sensitive guaiac test. Aliment Pharmacol Ther 2006;23:1359-64.

26. Fraser CG, Matthew CM, Mowat NA, Wilson JA, Carey FA, Steele RJ. Immunochemical testing of individuals positive for guaiac faecal occult blood test in a screening programme for colorectal cancer: an observational study. Lancet Oncol 2006;7:127-31. 
27. Hol L, Wilschut JA, Ballegooijen M, van Vuuren AJ, van der Valk $H$, Reijerink JC, van der Togt AC, Kuipers EJ, Habbema JD, van Leerdam ME. Screening for colorectal cancer: random comparison of guaiac and immunochemical faecal occult blood testing at different cut-off levels. Br J Cancer 2009;100:1103-10.

28. Guittet L, Bouvier V, Mariotte N, Vallee JP, Levillain R, Tichet J, Launoy $\mathrm{G}$. Comparison of a guaiac and immunochemical faecal occult blood test for the detection of colonic lesions according to lesion type and location. Br J Cancer 2009;100:1230-35.
29. Guittet L, Bouvier V, Mariotte N, Vallee JP, Arséne D, Boutreux S, Tichet J, Launoy G. Comparison of a guaiac based and immunochemical faecal occult blood test in screening for colorectal cancer in a general average risk population. Gut 2007;56:210-4.

30. Wilkins T, Reynolds PL. Colorectal cancer: a summary of the evidence for screening and prevention. Am Fam Physician 2008;78:1385-92. 